\title{
Fitness and Quality of Life Outcomes of Cancer Survivor Participants in a Community Exercise Program
}

RITA MUSANTI, PhD, APN-BC, YING-YU CHAO, PhD, GNP-BC, and KATELYN COLLINS, BS, RDN

From Rutgers Biomedical Health Sciences School of Nursing, The State University of New Jersey School of Nursing, Newark, New Jersey

Authors' disclosures of conflicts of interest are found at the end of this article.

Correspondence to: Rita Musanti, PhD, APN-BC, School of Nursing, Rutgers, The State University of New Jersey, 110 Paterson Street, New Brunswick, NJ 08901. E-mail: rmusanti@sn.rutgers.edu https://doi.org/10.6004/jadpro.2019.101.2 (1) 2019 Harborside ${ }^{T M}$

\begin{abstract}
Exercise is recommended for cancer survivors, as it mitigates treatment side effects and improves overall wellness. Therefore, survivors attend community-based exercise programs and report positive results, but published evaluations of outcomes of these programs are scarce in the literature. The objective of this study is to validate the anecdotal reports of the physical fitness and quality of life benefits of the LIVESTRONG at the YMCA program. A retrospective analysis of deidentified data consisting of 17 program cohorts of the LIVESTRONG at the YMCA program $(n=88)$ was conducted. Statistically significant improvements were seen when compared to baseline in the physical fitness measures of the 6-minute walk, the chest and leg presses, the sit-and-reach test, and the oneleg stand test, as well as in the domains of the 29-item Patient-Reported Outcomes Measurement Information System (PROMIS-29) Profile, a health-related quality of life questionnaire. These domains are physical function, anxiety, depression, fatigue, social role satisfaction, and pain. The anecdotal impression that participation in the LIVESTRONG at the YMCA program improves physical fitness and subjective quality of life perceptions was supported by statistical analysis of the subjective and objective pre- and postprogram measurements for this data set. Exercise in this cancer-specific community exercise program is likely to improve physical fitness and quality of life outcomes.
\end{abstract}

ancer will be diagnosed in approximately $39.6 \%$ of men and women during their lifetime, according to data collected by the Surveillance, Epidemiology, and End Results Program (SEER), of the National Cancer Institute (NCI, 2015). Early detection and improved treatments continue to positively impact cancer survivorship, such that $66.5 \%$ of patients diagnosed can now expect to be alive in 5 years (Howlader et al., 2016). These numbers combined indicate that by 2025 there will be 18.9 million cancer survivors in the United States, and of these, $75 \%$ will be greater than 50 years of age (American Cancer Society, 2016). 


\section{SURVIVORSHIP GUIDELINES}

For many diagnosed with cancer, survivorship means living with cancer as a chronic condition, while for others, although there may be no evidence of the cancer, there are bothersome longterm and persistent effects. The goal in cancer survivorship care is to provide the tools for survivors to live as healthy a life as possible, one devoid of additional chronic illness, and one in which late effects are minimized (Smith et al., 2013).

To that end, a physically active lifestyle is recommended for cancer survivors as a means of improving feelings of well-being, decreasing risk of developing chronic conditions such as heart disease and metabolic disorders such as obesity and diabetes mellitus, and decreasing the risk of new or recurrent cancer (Centers for Disease Control and Prevention [CDC], 2014; Holmes, Chen, Feskanich, Kroenke, \& Colditz, 2005; Meyerhardt et al., 2006).

Professional, governmental, and public advocacy organizations such as the National Cancer Institute (NCI), the American Society of Clinical Oncology (ASCO), the Oncology Nursing Society (ONS), the American College of Sports Medicine (ACSM), and the American Cancer Society (ACS) have all issued statements and provided guidelines to cancer survivors regarding physical activity (ASCO, 2016; NCI, 2017; ONS, 2016; Rock et al., 2012; Schmitz et al., 2010).

In general, cancer survivors are encouraged to meet the current CDC recommendation of 150 minutes of moderate aerobic exercise per week, or 75 minutes of vigorous exercise, or a combination of the two, plus resistance exercise of the major muscle groups at least 2 times per week. This comes with the caveat that many cancer survivors will be unable to meet these goals, and in those cases, altering the goal to maximize physical fitness to the highest degree achievable is recommended (Office of Disease Prevention and Health Promotion, 2008). These recommendations have been translated into community-based exercise programs for cancer survivors.

\section{LIVESTRONG AT THE YMCA}

One such program is LIVESTRONG at the YMCA, a program developed by LIVESTRONG and YMCA of the USA (often referred to as the Y or Y-USA). The LIVESTRONG at the YMCA pro- gram is available through participating YMCAs nationwide (Heston, Schwartz, Justice-Gardiner, \& Hohman, 2015). The goal of the LIVESTRONG at the YMCA program is to empower adult cancer survivors to practice a healthy lifestyle. Specifically, the program is aimed at increasing muscle mass, physical strength, and cardiopulmonary endurance, with the resultant benefits of improving daily functional ability, personal energy levels, self-esteem, and quality of life.

The program is led by specially trained YMCA instructors who lead a cohort of survivors through small-group sessions that meet twice a week for 75 minutes for 12 weeks. The program is open to all cancer survivors over the age of 18 who are undergoing or who have completed their treatments.

Participants are invited to enroll in these programs via brochures distributed at the YMCA sites, as well as in local cancer care and support centers, website postings, and at local cancerrelated events. Cancer survivors must obtain physician clearance before joining the program. Prior to initiating the exercise component of the program, the $\mathrm{Y}$ intake staff members meet with each participant individually to explain the program and gather health and demographic information. Additionally, participants consent to participation and to the use of their data for aggregate program analysis. Participant fitness and quality of life assessments are obtained at the start of the program and again on week 12. These assessments are used by the instructors to adapt the program's curriculum to each participant. The twice-weekly exercise sessions include aerobic, resistance, and balance exercises. Exercise and equipment modifications/adaptations are incorporated as necessary to maintain safety and effectiveness.

\section{OBJECTIVES}

There are only a few published reports of aggregate data analysis of program measured outcomes (Rajotte et al., 2012; Tran et al., 2016). Therefore, we undertook a retrospective program analysis of deidentified data collected at three LIVESTRONG at the YMCA sites in New Jersey and Pennsylvania to add to the evaluation literature of this community program and to determine if regional differences exist, as the other studies did not use samples from the Northeast. 


\section{SAMPLE AND SETTING}

This was a retrospective analysis that used existing deidentified physical fitness and quality of life data of cancer survivors from three sites in the suburban to the metropolitan areas of New York and Philadelphia (Site 1, n = 29; Site 2, $\mathrm{n}=18$; Site 3, $\mathrm{n}=41$; see Table 1). The data were collected as part of the LIVESTRONG at the YMCA programs that were held between July 2011 and June 2013. Data from this convenience sample were collected at the start and the end of the 12-week LIVESTRONG at the YMCA programs.

\section{METHODS AND VARIABLES}

\section{Demographic and Medical History}

All participants self-reported their age, gender, cancer diagnosis, cancer treatment type and completion date, the presence of peripheral neuropathy, current comorbid conditions, their current work status, and whether or not they engage in routine exercise.

\section{Physical Fitness Assessment}

All physical fitness assessments were done by the Y staff. Cardiopulmonary function was assessed via the results of the 6-minute walk test. The 6-minute walk test is a standard test of cardiopulmonary endurance in which participants cover as large a distance as possible over 6 minutes. It is done on a measured track 25 meters in length. The total meters walked are measured, and this is the score. It is used extensively as a field measure of cardiopulmonary fitness, with norms available for all age groups, in well populations, and in numerous chronically ill populations. In the cancer population it is considered a valid and reliable cardiopulmonary test (Schmidt, Vogt, Thiel, Jäger, \& Banzer, 2013).

Strength measurement was obtained via the one-repetition maximum (1-RM) test for the bench press and leg press. The 1-RM test is the standard for evaluating increases in muscular strength (Baechle \& Wathen, 2008). Flexibility and balance are measured using the arm reach test and the one-leg stance test, respectively (Springer, Marin, Cyhan, Roberts, \& Gill, 2007).

\section{Quality of Life Assessment}

The Patient-Reported Outcomes Measurement Information System (PROMIS; Cella et al., 2007) is a series of valid and reliable self-reported measurement tools provided by the National Institutes of Health for use by researchers and clinicians (US Department of Health and Human Services [USDHHS], 2016). The LIVESTRONG at the YMCA program uses the PROMIS-29 Profile (v1.01) to measure health-related quality of life, which includes the subdomains of anxiety, depression, pain interference, pain intensity, physical function, sleep disturbance, and ability to participate in social roles and activities.

Each subdomain is considered an individual form and scored separately. Each form is four items, except pain intensity, which is a one-item form. The single pain intensity item is not scored but reported as its raw score, that is, on a 0 to 10 scale, with 0 equivalent to no pain and 10 the greatest intensity of pain. Each subdomain form is only scored if there are no missing item scores (i.e., all four items are marked). If the form is incomplete, then that domain score is not considered valid. The raw scores (range, 1-20) are converted to a $\mathrm{T}$-score, with the average being 50 and a standard deviation of 10 .

The PROMIS-29 Profile domains were originally tested on a large sample of the general population in the United States. For all domains, a higher score means more of the state is present, so a high physical function score means greater function, and a high sleep disturbance score means more of a problem with sleep. Therefore, when we intervene to improve quality of life, we hope to see increased scores in physical function and social role satisfaction, and decreased scores in anxiety, depression, fatigue, and pain interference (USDHHS, 2016).

\section{Data Abstraction and Statistical Analysis}

Statistical analysis was carried out using SPSS statistics software, version 25 . The significance level was set at $5 \%$ for all tests. Deidentified data sets from 17 program cohorts (101 participants) were used for study analysis. Participant characteristics are reported as mean and standard deviation. Categorical variables are reported as the actual number. The demographic variables of age and comorbidity were transformed into categorical variables for analysis. Age was categorized as (1) 20-39; (2) 40-49; (3) 50-59; (4) 60-69; and 


\section{Table 1. Crosstabulation of Participant Characteristics by Site}

\begin{tabular}{|c|c|c|c|c|c|c|}
\hline & & $\begin{array}{l}\text { S1 } \\
(n=29)\end{array}$ & $\begin{array}{l}52 \\
(n=18)\end{array}$ & $\begin{array}{l}s 3 \\
(n=41)\end{array}$ & $\begin{array}{l}\text { Total } \\
(n=88)\end{array}$ & Significance \\
\hline $\begin{array}{l}\text { Mean age } \\
\text { (SD) }\end{array}$ & & $\begin{array}{l}58 \\
(13.9)\end{array}$ & $\begin{array}{l}56 \\
(11)\end{array}$ & $\begin{array}{l}56 \\
(11)\end{array}$ & $\begin{array}{l}57 \\
(12)\end{array}$ & $\begin{array}{l}F(2,87)=.197 \\
p=.822\end{array}$ \\
\hline \multirow[t]{5}{*}{ Age } & $20-39$ & 4 & 1 & 3 & 8 & \multirow{5}{*}{$\begin{array}{l}\text { Fisher's exact test } \\
p=.537\end{array}$} \\
\hline & $40-49$ & 5 & 5 & 9 & 19 & \\
\hline & $50-59$ & 3 & 6 & 12 & 21 & \\
\hline & $60-69$ & 11 & 4 & 11 & 26 & \\
\hline & $\geq 70$ & 6 & 2 & 6 & 14 & \\
\hline \multirow[t]{2}{*}{ Gender } & Male & 7 & 4 & 4 & 15 & \multirow{2}{*}{$\begin{array}{l}\text { Fisher's exact test } \\
p=.224\end{array}$} \\
\hline & Female & 22 & 14 & 37 & 73 & \\
\hline \multirow[t]{8}{*}{ Cancer type } & Breast & 13 & 7 & 22 & 42 & \multirow{8}{*}{$\begin{array}{l}\text { Fisher's exact test } \\
p=.470\end{array}$} \\
\hline & Colon & 2 & 1 & 6 & 9 & \\
\hline & Lung & 2 & 0 & 3 & 5 & \\
\hline & Heme & 2 & 2 & 0 & 4 & \\
\hline & Prostate & 2 & 1 & 1 & 4 & \\
\hline & Gyn & 4 & 2 & 1 & 7 & \\
\hline & Lymphoma & 2 & 1 & 2 & 4 & \\
\hline & Other & 3 & 4 & 6 & 13 & \\
\hline \multirow[t]{2}{*}{ Comorbidity } & $\leq 2$ & 15 & 10 & 20 & 45 & \multirow{2}{*}{$\begin{array}{l}\chi^{2}(2)=.236 \\
p=.889\end{array}$} \\
\hline & $>2$ & 14 & 8 & 21 & 43 & \\
\hline \multirow[t]{7}{*}{ Treatment } & Sx & 6 & 1 & 4 & 11 & \multirow{7}{*}{$\begin{array}{l}\text { Fisher's exact test } \\
p=.554\end{array}$} \\
\hline & CT & 2 & 1 & 1 & 4 & \\
\hline & $\mathrm{RT}$ & 1 & 0 & 1 & 2 & \\
\hline & $\mathrm{Sx}+\mathrm{CT}$ & 7 & 5 & 13 & 25 & \\
\hline & $S x+R T$ & 6 & 2 & 5 & 13 & \\
\hline & $\mathrm{CT}+\mathrm{RT}$ & 2 & 0 & 2 & 4 & \\
\hline & $\mathrm{S} x+\mathrm{CT}+\mathrm{RT}$ & 5 & 9 & 15 & 29 & \\
\hline \multirow[t]{2}{*}{ Symptoms ${ }^{a}$} & Yes & 15 & 12 & 32 & 59 & \multirow{2}{*}{$\begin{array}{l}\chi^{2}(2)=3.84 \\
p=.155\end{array}$} \\
\hline & No & 12 & 6 & 9 & 27 & \\
\hline \multirow[t]{2}{*}{ Work } & Yes & 16 & 9 & 13 & 38 & \multirow{2}{*}{$\begin{array}{l}\chi^{2}(2)=4.22 \\
p=.126\end{array}$} \\
\hline & No & 13 & 9 & 28 & 50 & \\
\hline \multirow[t]{2}{*}{ Exercise } & Yes & 15 & 11 & 29 & 55 & \multirow{2}{*}{$\begin{array}{l}\chi^{2}(2)=3.51 \\
p=.174\end{array}$} \\
\hline & No & 14 & 7 & 14 & 33 & \\
\hline
\end{tabular}

(5) > 69; and comorbidities were dichotomized as either $\leq 2$ or $>2$ comorbidities.

Assessment of Participant Characteristics by Site. The evaluation of participant characteris- tics by site was carried out using the chi-square test of independence when all expected frequencies were greater than 5 , or the Fisher's exact test when expected frequencies were less than 5 . 
Data Preparation. Thirteen individuals provided no outcome data and were not considered in the final analysis. Missing data were not replaced for physical fitness data, and cases were excluded casewise during analysis for each physical fitness parameter. The few randomly missing item values in the PROMIS-29 domains were replaced by moving the pretest item value forward (USDHHS, 2016). For all outcome variables, there were no extreme outliers ( $>3$ standard deviations from the mean) as assessed by boxplot, and data were evaluated for normality by the Shapiro-Wilk test and scatterplot analysis. In the case that a variable was not normally distributed, data were either transformed or a test not sensitive to normality was utilized for analysis.

Gender Effect. Physical fitness outcomes are not gender neutral, and there were significantly fewer men than women ( 15 vs. 73 ) in these data, so the analyses were conducted on the data set split by gender.

\section{Analytic Approach}

Effect of Program Participation on PROMIS-29 and Physical Fitness Scores for the Overall Sample. A paired-sample t-test was used to determine if there was a statistically significant change in scores between baseline and the postprogram time point. Data are presented as mean \pm standard deviation. For each domain score, the T-score for each raw score was derived from PROMIS-29 scoring tables and is presented.

Program Participation and Participant Characteristics: Main and Interaction Effects on Physical Fitness Outcome Measures. A two-way repeated measure analysis of variance (ANOVA; within, within and between groups approach) was conducted to determine if there were statistically significant differences in the mean change in the physical fitness outcomes from baseline to postprogram time points due to interaction and main effects. The interaction of the time factor (within factor \#1-participating in the LIVESTRONG program) and the categorical variable (within factor \#2) were analyzed in separate ANOVA runs using the categorical variables of age category, cancer type, cancer treatment, comorbid category, presence of peripheral neuropathy (symptom), working status, and exercise status.
The main effects of these categorical variables were included in the analysis. The intent of this analysis was to determine if there was (1) an interaction between participation in the program and the participant characteristics of age category, comorbidity category, type of disease, type of treatment, presence of peripheral neuropathy, and self-reported work and exercise status at baseline on physical fitness outcome measures; and (2) if there was a differential effect due to the level of the characteristic category on physical fitness outcomes (for example, was there a difference in strength measure by virtue of being in the 20-39 age category vs. $>70$ age category?).

For these analyses, homogeneity of variance was assessed using Levene's test for equality of variances. If violated data were subjected to a $\log 10$ transformation, and in the case where results were unchanged and the variance differences were less than $3 \%$, untransformed data are reported. It should be noted that due to the fact that not all participants completed all physical fitness tests at the end of the program, the sample size varies across these outcomes. Only significant findings are reported.

\section{RESULTS}

\section{Sample}

There were no statistically significant differences in the participant characteristics across the sites, and so data were analyzed as a single group. Self-reported demographic and medical history data indicated that most participants had completed treatment within the past 2 years $(62 \%)$, followed by those who had completed treatment greater than 5 years ago (18\%), followed by those currently being treated (10\%), and then by those between 2 and 5 years since treatment (10\%). The majority of the participants were women (83\%). Breast cancer was the most frequently cited diagnosis (48\%). The remaining participants represented individuals with a range of cancers, including colorectal (10\%), hematologic malignancies including lymphomas (9\%), gynecologic (8\%), lung (6\%), prostate $(5 \%)$, and other (14\%). Comorbidities were reported by $70 \%$ of participants, with most patients experiencing more than two comorbidities (49\%). Cardiometabolic problems (hypertension, high 
cholesterol, and unspecified cardiac problems) were reported by $32 \%$, unspecified pulmonary problems by $18 \%$, and arthritis by $32 \%$. Interestingly, diabetes mellitus was negligible, at .04\% of the participants. The presence of peripheral neuropathy was reported by $67 \%$ (59) of the participants in this sample. Of those, $81 \%$ (48) had had chemotherapy, a major cause of peripheral neuropathy in cancer survivors. By cancer type, those who had a chemotherapy history and peripheral neuropathy were survivors of breast cancer (44\%), colorectal and gynecologic cancers (both $13 \%$ ), other cancers (14\%), lung (8\%), lymphoma (4\%), and prostate and hematologic malignancies $(2 \%)$.

\section{Overall Changes in PROMIS-29 Scores and Physical Fitness Scores}

Results of the paired-samples t-test are presented in Tables 2 and 3 for the physical fitness tests and PROMIS-29 domains, respectively. Statistically significant improvements in cardiopulmonary fitness (heart rate and 6-minute walk), muscular strength (leg and chest presses), flexibility (sitand-reach test) and balance (single-leg stand) were noted for all tests in women; in men, the heart rate and left-sided balance did not change significantly.

\section{Program Participation and Participant} Characteristics: Main and Interaction Effects on Physical Fitness Outcome Measures

Male Participants. There was only one significant interaction for the categorical variables on the physical fitness outcome measures. A significant interaction between participation and age category on flexibility occurred, with men in the 20 to 39 age category responding more vigorously, as exhibited by a 5- vs. 1-inch increase in their ability from baseline to program end $(F=5.27$ $(4,7), p=.028)$.

Female Participants. A significant interaction was noted between participation in the program and the following.

- Age category on strength (leg press; $F=4.80$ $\left.(4,65), p=.002, \eta^{2}=.23\right)$, with the 20 to 39 age category responding more vigorously, as exhibited by an increase of $75 \mathrm{lb}$ in lifting ability, compared to $30 \mathrm{lb}$ for the 60 to 69 age category, and $14 \mathrm{lb}$ for the $>70$ age group.

- Presence of the peripheral neuropathy symptom on balance (left-leg stand; $F=7.40$ $\left.(1,44), p=.008, \eta^{2}=.15\right)$, with those participants not having the symptom responding more vigorously, as exhibited by an increase of 6 seconds vs. 4 seconds balance ability,

\begin{tabular}{|c|c|c|c|c|}
\hline Outcome & Gender (n) & Pretest mean \pm SD & Posttest mean \pm SD & Significance \\
\hline \multirow{2}{*}{$\begin{array}{l}\text { Heart rate } \\
\text { (beats/minute) }\end{array}$} & $M(14)$ & $91.36 \pm 18.95$ & $97.92 \pm 13.15$ & .124 \\
\hline & $F(65)$ & $93.63 \pm 15.05$ & $89.00 \pm 17.45$ & .007 \\
\hline \multirow{2}{*}{$\begin{array}{l}\text { 6-minute walk test } \\
\text { (distance in meters) }\end{array}$} & $M(10)$ & $364.47 \pm 139.61$ & $421.98 \pm 129.31$ & .008 \\
\hline & $F(59)$ & $457.98 \pm 104.56$ & $523.73 \pm 122.23$ & .000 \\
\hline \multirow[t]{2}{*}{ Leg press (Ib) } & $M(14)$ & $222.86 \pm 72.58$ & $271.79 \pm 87.90$ & .000 \\
\hline & $F(70)$ & $110.79 \pm 46.34$ & $144.12 \pm 52.63$ & .000 \\
\hline \multirow[t]{2}{*}{ Chest press (Ib) } & $M(14)$ & $88.86 \pm 43.96$ & $113.21 \pm 55.35$ & .000 \\
\hline & $F(68)$ & $27.00 \pm 15.06$ & $35.88 \pm 18.47$ & .000 \\
\hline \multirow[t]{2}{*}{ Arm reach (inches) } & $M(12)$ & $37.75 \pm 8.74$ & $39.18 \pm 8.40$ & .05 \\
\hline & $F(47)$ & $37.91 \pm 5.65$ & $39.14 \pm 6.5$ & .04 \\
\hline \multirow{2}{*}{$\begin{array}{l}\text { Single-leg stand (L) } \\
\text { (seconds) }\end{array}$} & M 12) & $25.42 \pm 23.50$ & $25.00 \pm 22.30$ & .881 \\
\hline & $F(48)$ & $32.61 \pm 23.03$ & $41.65 \pm 21.35$ & .000 \\
\hline \multirow{2}{*}{$\begin{array}{l}\text { Single-leg stand (R) } \\
\text { (seconds) }\end{array}$} & $M(12)$ & $28.33 \pm 22.52$ & $34.08 \pm 21.34$ & .04 \\
\hline & $F(48)$ & $32.81 \pm 23.22$ & $40.59 \pm 22.38$ & .000 \\
\hline
\end{tabular}


Table 3. Paired-Samples T-Test: PROMIS-29 Raw Scores With Associated Standardized Score

\begin{tabular}{|c|c|c|c|c|c|c|}
\hline Domain ${ }^{a}$ & Gender & $\begin{array}{l}\text { Pretest raw } \\
\text { score mean } \pm \text { SD }\end{array}$ & T-score range ${ }^{b}$ & $\begin{array}{l}\text { Posttest raw } \\
\text { score mean } \pm \text { SD }\end{array}$ & T-score range & $\begin{array}{l}\text { Significance } \\
\text { raw score } \\
\text { change }\end{array}$ \\
\hline \multirow{2}{*}{$\begin{array}{l}\text { Physical } \\
\text { function }\end{array}$} & Male & $17.7 \pm 2.12$ & $41.8<45.3<56.9$ & $18.26 \pm 2.12$ & $41.8<45.3<56.9$ & .164 \\
\hline & Female & $17.78 \pm 2.15$ & $41.8<45.3<56.9$ & $18.93 \pm 1.49$ & $43.4<48<56.9$ & .000 \\
\hline \multirow[t]{2}{*}{ Anxiety } & Male & $6.73 \pm 2.01$ & $48<53.7<55.8$ & $6.0 \pm 2.36$ & $40.3<51.2<55.8$ & .215 \\
\hline & Female & $8.15 \pm 3.12$ & $48<55.8<61.4$ & $6.22 \pm 2.55$ & $40.3<51.2<57.7$ & .000 \\
\hline \multirow[t]{2}{*}{ Depression } & Male & $6.87 \pm 1.68$ & $49<53.9<57.3$ & $4.67 \pm 1.18$ & $41<49<51.8$ & .000 \\
\hline & Female & $6.51 \pm 2.61$ & $41<53.9<57.3$ & $5.00 \pm 1.75$ & $41<49<53.9$ & .000 \\
\hline \multirow[t]{2}{*}{ Fatigue } & Male & $10.40 \pm 3.89$ & $43.1<53.1<60.7$ & $8.86 \pm 3.07$ & $43.1<51<57$ & .068 \\
\hline & Female & $9.71 \pm 3.61$ & $43.1<53.1<58.8$ & $7.68 \pm 3.27$ & $33.7<48.6<55.1$ & .000 \\
\hline \multirow{2}{*}{$\begin{array}{l}\text { Sleep } \\
\text { disturbance }\end{array}$} & Male & $10.73 \pm 2.15$ & $48.4<50.5<56.1$ & $7.33 \pm 1.54$ & $41.1<43.8<48.4$ & .000 \\
\hline & Female & $11.01 \pm 1.60$ & $48.4<52.4<56.1$ & $12.17 \pm 2.95$ & $48.4<54.3<59.8$ & .002 \\
\hline \multirow{2}{*}{$\begin{array}{l}\text { Satisfaction } \\
\text { with social role }\end{array}$} & Male & $14.87 \pm 4.39$ & $48.1<49.8<58.1$ & $15.47 \pm 3.98$ & $44.6<51.6<64.1$ & .503 \\
\hline & Female & $13.88 \pm 3.27$ & $43.2<48.1<53.5$ & $15.18 \pm 3.72$ & $44.8<49.8<58.1$ & .003 \\
\hline \multirow{2}{*}{$\begin{array}{l}\text { Pain } \\
\text { interference }\end{array}$} & Male & $7.8 \pm 3.57$ & $41.6<55.6<59.9$ & $6.27 \pm 2.81$ & $41.6<52<57.1$ & .038 \\
\hline & Female & $7.77 \pm 3.21$ & $49.6<55.6<59.9$ & $6.70 \pm 3.32$ & $41.6<53.9<58.5$ & .000 \\
\hline
\end{tabular}

and on the right-leg stand $(F=3.94(1,44)$, $\left.p=.05, \eta^{2}=.08\right)$, the difference in this case being 10 seconds greater stance time for the no-symptom group.

- Exercise behavior at baseline on balance (right-leg stand; $F=7.21$ (1,43), $p=.010, \eta^{2}$ $=.079)$, with exercisers responding more vigorously at 14 seconds compared to a 4 second increase for those who did not report baseline exercise behavior.

A significant main effect was found between participation in the program and the following.

- Age on balance, with the 20 to 39 age category having a significantly longer balance time (36 vs. 21 seconds) in left leg balance compared to the $>70$ age category $(F=2.92(4,43), p=$ .031). There was a decremented decrease in balance over age categories, but other differences were not statistically significant.

- Age on strength was noted, with the 20 to 39 age category having significantly greater mean strength (188 lb vs. $115 \mathrm{lb})$ compared to the 50-59 age category $(p=.006)$ and the 70 age category (188 lb vs. $101 \mathrm{lb}(p=.002)$. There was a decremented decrease in mean strength scores over the age categories from youngest to oldest.

- Cancer type on cardiopulmonary fitness (6-minute walk) was noted, with breast cancer survivors differing significantly from colorectal cancer survivors $(p=.041)$, who differed significantly from those with lymphoma ( $p=.04$; mean scores of 548,429 , and 647 meters, respectively; $F=3.61(5,53)$, $p=.007)$. Of note, lung cancer patients started out with the lowest distance, at 333 meters, but mean postdistance in this group was 444 meters.

- Work on cardiopulmonary fitness (6-minute walk) was noted, with participants who reported not working having significantly longer walking distances (516 meters vs. 445 meters) than those who were working ( $F=$ $6.11(1,54), p=.017)$.

- Exercise on cardiopulmonary fitness (6minute walk) was noted, with participants who reported exercise at baseline having significantly longer walking distances (512 $\mathrm{m}$ vs. $450 \mathrm{~m}$ ) than those who did not exercise at baseline $(F=4.73(1,54), p=.034)$. 
Follow-Up Analysis. Given the findings related to cardiopulmonary fitness and work, a univariate ANOVA was run to determine if there was a difference in the mean level of fatigue, using baseline fatigue as a covariate and working as a random factor. There was no significant difference based on the working category $(F=.865(1,67) ; p=.356)$.

\section{DISCUSSION}

Exercise recommendations for cancer survivors have been translated into community exercise programs such as LIVESTRONG at the YMCA. Anecdotal evidence gleaned from survivors in our communities frequently support this program's positive impact on physical fitness and quality of life. Although outcome evaluations have been reported in the literature, they are not reported frequently, and those that have been reported have not included our geographic region. Therefore, we undertook an analysis of existing data at three LIVESTRONG at the YMCA programs sites located within suburban communities in the New Jersey and Pennsylvania metropolitan area. The purpose was to see if our results concur with reports that fitness and quality of life is improved for participants of these programs.

\section{Participant Characteristics}

In general, the characteristics of the participants in our sample were similar to those that have been reported in community program evaluations and exercise-focused research studies. The majority of participants enrolled in our programs were women, and breast cancer was the most frequently reported cancer diagnosis. This gender- and cancer-specific profile is consistent with reports in the literature regarding the demographics of participants in cancer rehabilitation and exercise program studies (Mishra et al., 2012; Rajotte et al., 2012; Scott et al., 2013).

There are several reasons for a greater uptake of exercise by breast cancer survivors. First, they were the first survivors to be studied with respect to the risks and benefits of exercise (Molinaro, Kleinfeld, \& Lebed, 1986; Winningham \& MacVicar, 1988). Over the years, exercise studies have focused almost exclusively on breast cancer survivors, and most of the evidence we have for the benefits of exercise in cancer survivors derives from these studies (Spence, Heesch, \& Brown, 2010). This is changing, and a body of knowledge regarding exercise in other cancers is emerging. Second, in addition to the research focus, breast cancer survivor advocacy groups, such as the Susan G. Komen Foundation, have promoted exercise for breast cancer survivors through community activities such as $5 \mathrm{~K}$ races and walks (Susan G. Komen Race for the Cure, 2016). Breast cancer survivors are encouraged to participate, and many do so. Additionally, breast cancer survivors have opportunities to engage in survivor-specific team sports, such as dragon boat racing. Interest in this sport has resulted in the creation of a formal organization with regional, national, and international competitions held under the auspices of the International Breast Cancer Paddlers' Commission (IBCPC, 2016). Finally, based on these movements within the breast cancer population, oncology health-care providers, family, and friends are well aware that exercise is a beneficial activity that is safe and recommended.

The stimulus to encourage exercise behavior beyond the breast cancer population to other cancer populations is ongoing. Although the participation of survivors with other cancers may remain disproportionate, the message to include all survivors in cancer exercise programs is made clearly through exercise guidelines for cancer survivors and publications on assessment and prescribing (see ACSM Roundtable Discussion on Exercise Guidelines [Schmitz et al., 2010; Stefani, Galanti, and Klika, 2017] and the Clinical Journal of Oncology Nursing Exercise Supplement [Musanti \& Murley, 2016]).

The frequency of comorbidities was noted in $70 \%$ of the participants in this sample. In a recent study, Roy and colleagues (2018) found a higher prevalence of cardiac-related diseases (hypertension, hyperlipidemia, coronary artery disease), hypothyroidism, and diabetes in cancer survivors ( $n=280)$ compared to their age-matched controls $(n=280)$. Osteoarthritis was less prevalent in the cancer survivor group, although it has been reported in other studies as a significant comorbidity in comparison to the general population (Deckx et al., 2012). Our analysis yielded a similar pattern of comorbidities, with the exception of diabetes, which was rarely reported in this sample. 
The evidence for exercise ameliorating morbidity risks related to these comorbid conditions makes a compelling case for recommending exercise as a lifestyle habit for all cancer survivors (CDC, 2015). Although we do not have outcome measures in this analysis that support the improvement of any of these comorbid conditions, we do have evidence that participation in the exercises targeted at cardiopulmonary function, strength, flexibility, and balance did indeed improve physical fitness outcomes: measures of cardiopulmonary function (6-minute walk), strength (leg and chest presses), flexibility (sit-and-reach test), and balance (singleleg stand). These improvements translated to congruent improvements in perceptions of physical function, decreased fatigue, and decreased pain. Taken together, due to participation in the LIVESTRONG at the YMCA program, the physical fitness and self-reported improvements are consistent with the potential for decreased risk of chronic disease progression, improvement in psychological functioning, and decreases in pain, which have been associated with habitual exercise behavior (CDC, 2018).

Peripheral neuropathy was reported at a higher frequently (67\%) in our sample than is commonly reported in the literature (30\% to 40\%; Staff, Grisold, Grisold, \& Windebank, 2017). Chemotherapy-induced peripheral neuropathy (CIPN) is the likely cause, and almost all (95\%) of participants who reported this symptom had had chemotherapy. The range of chemotherapeutics that can cause neurotoxicity include agents such as the taxanes, the platinum compounds, vinca alkaloids, proteasome inhibitors, and the newer immune checkpoint inhibitors. The risk, the nature of the symptom, and the trajectory of the symptom are individual, multifactorial, and complex, but preventing or minimizing impact is always a primary goal.

In addition to the pain associated with CIPN, the functional impairment in the form of altered proprioception is of concern because it alters balance and limits physical activity, with subsequent effects on safe mobility and an increased risk of falls. Intact proprioception, balance, and flexibility are important attributes that guard against falls, an event for which community cancer survivors may be at increased risk. The rate of falls in community cancer survivors is reported at between $20 \%$ to $30 \%$ when assessed retrospectively in time periods of 3 to 12 months (Wildes, Depp, Colditz, \& Stark, 2016). Evidence is accumulating that a combined exercise protocol consisting of aerobic, resistance, and proprioception training is effective in mitigating the symptoms of peripheral neuropathy (Kleckner et al., 2018). Consistent with our findings, studies specific to cancer survivors are providing evidence that proprioceptive training improves flexibility and dynamic balance in cancer survivors, particularly when introduced during the treatment phase (Duregon et al., 2018; Emilio et al., 2014).

Moreover, exercise has been identified as an intervention that prevents falls in community adults (Gillespie et al., 2012). We saw a statistically significant interaction between having peripheral neuropathy or not on the level of increase in balance scores, with those without the symptom improving more than those with the symptom. More research needs to be done in this area with a focus on all cancer survivors, but with attention to the design and timing of effective exercise programing, particularly for those at greatest risk of injury-older survivors receiving neurotoxic chemotherapy.

\section{Self-Reported Quality of Life Scores}

Participant perceptions measured with the PROMIS-29 Profile were significantly improved in the domains of physical function, anxiety, depression, fatigue, social role satisfaction, and pain interference when compared to baseline scores, for both men and women. Sleep disturbance was less of a problem for men at the end of the program; for women, scores indicated that it was more of a problem (see Figure 1). Generally, with the exception of the sleep finding, our results concur with what Shiraz and colleagues found in their 2012 meta-analysis of exercise interventions on health-related quality of life of cancer survivors (Shiraz, Rahtz, Bhui, Hutchison, \& Korszun, 2014) and with the findings of Rajotte and colleagues, who studied a group of cancer survivors enrolled in LIVESTRONG at the YMCA in the Northwest region of the United States ( $\mathrm{n}=187$; Rajotte et al., 2012). In the later study, survivors self-reported improve- 


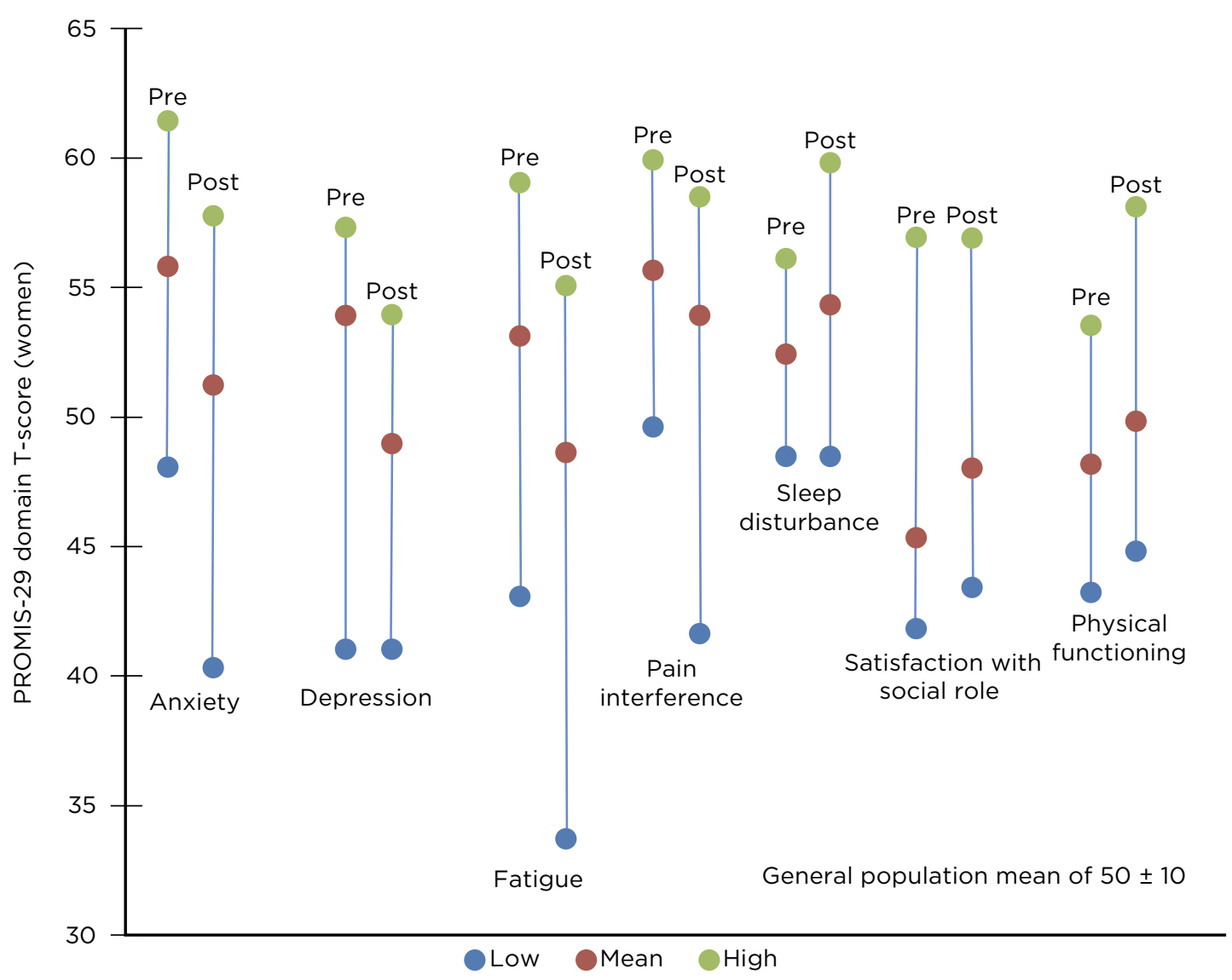

Figure 1. Patient-Reported Outcomes Measurement Information System with a 29-item short-form health-related quality of life measure (PROMIS-29) domain scores (women). Population mean of 50 with a standard deviation of 10. Anxiety, depression, fatigue, pain, and sleep disturbance improve with a lower score; physical function and satisfaction with role improve with a higher score.

ments in physical function; body pain; social, emotional, and role functions; mental function; fatigue; and insomnia. Participants used the RAND 36-Item Short Form Health Survey (SF36; Rand Corporation, 2016), the Fatigue Symptom Inventory (Hann et al., 1998), and a studydeveloped insomnia questionnaire. Adding our analysis to these previous reports positions us to conclude that quality of life improves when cancer survivors engage in regular physical activity, and in particular through participation in the LIVESTRONG at the YMCA program.

The PROMIS-29 Profile measures were originally tested for validity in a sample of adults with and without chronic disease. If we reflect on our findings in comparison to these population norms, we see that on average, the participants in our analysis negatively deviated from the norm at baseline in all domains. Conversely, at the end of the program, all domains except sleep disturbance either approached the mean or surpassed the mean (i.e., they improved beyond the population norm). The numbers are not dramatic, and all are less than a one-standard deviation change (score change of 10 on T-score), but the pattern is what we want to see and is descriptive of a positive effect.

The lack of a change in sleep disturbance may be related to measurement error, as this scale had two negatively and two positively worded items, increasing the possibility of measurement and/ or scoring error. For this reason, we consider this result with caution. Another consideration with respect to these score changes is the fact that in addition to the statistical significance, we should consider the clinical significance of these im- 
provements. As with many interventions, once we observe statistically significant change, it is incumbent upon us as researchers and health-care providers to further investigate our interventions with regard to meaningful, clinically significant change so we have a better gauge of our impact on people's health and lives. In the case of exercise, we would hope that the clinical significance of these self-reported improvements would be enough to translate into the adoption of sustained exercise behavior.

\section{Physical Fitness Objective Outcomes}

The health-related physical fitness parameter measurements of cardiopulmonary fitness, muscular strength, flexibility, and balance exhibited statistically significant improvements from the preintervention to the postintervention assessments. The surrogate measurement for cardiopulmonary fitness, the 6-minute walk, was recently validated against VO2 peak testing (the gold standard for cardiopulmonary fitness testing) in 50 cancer survivors and found to be reliable ( $\mathrm{r}=.93$; Schmidt et al., 2013).

Although the mean scores in our analysis revealed that the participants were below the population norm (400-700 meters depending on age, height, weight, and gender) and that of those in the validation study (594 \pm 81 meters), the participants increased their distance walked on average by 58 meters for men and 66 meters for women. These improvements surpass the threshold set for the minimally clinically important difference (MCID) of 50 meters for adults. There is no MCID for the cancer survivor population (The Rehabilitation Institute of Chicago, 2015). As noted earlier, improvement in cardiopulmonary fitness has implications for not only improving functional performance but also diminishing the risk related to cardiometabolic disease.

The strength measurements of weight lifted during the chest and leg presses increased in a time-dependent and age-dependent manner; that is, in general, strength was gained between premeasurements and postmeasurements, but younger survivors improved more dramatically than older survivors over the course of the program. This is consistent with the age-dependent response of the physiologic milieu of the neuromuscular sys- tem in younger adults. Unfortunately, we can only evaluate the weight lifted measurements relative to the before and after scores; comparisons to population norms cannot be made because strength norms are reported as a ratio of weight lifted/body weight by gender and age. Participant weight data were not collected, rendering this calculation impossible. However, based on our understanding of muscular strength training, an increase in weight lifting capability is consistent with an ability to do more work with less effort.

In addition to the interaction we discussed, we noted several main effects. Some of these are expected and consistent with normal physiologic maturation; for example, strength and balance measures were of greater magnitude in younger vs. older survivors, and those individuals that re-ported exercise at baseline performed better on the 6-minute walk. These are expected findings. Others are not so expected and would require future study in larger samples for adequate exploration.

One example is the main effect of cancer type on cardiopulmonary fitness. Our analysis indicated that having colorectal cancer negatively impacted the 6-minute walk more so than having either breast cancer or lymphoma. The same relationship held true for individuals who were working compared to those who were not working, in spite of fatigue level not differing between these two groups. Gaining understanding of the differential impact these factors have on physical fitness outcomes will inform our ability to design more effective exercise programs for cancer survivors.

Limitations. This data analysis was retrospective and as such is limited in the conclusions we can draw, as well as the generalizability of the findings. However, these limitations inform us of the value of a prospective study with a larger sample size, consistent data collection techniques across sites, and a more robust data collection schema-one that includes such parameters as height, weight, more specific exercise program parameter descriptions, along with the utilized individual adaptive annotations, missed sessions, and reasons for participant withdrawal. Having this additional information would have provided a richer analysis and more robust conclusions. 


\section{IMPLICATIONS FOR}

\section{ADVANCED PRACTITIONERS}

We have reported positive objective and subjective findings related to physical fitness and psychological functioning in a sample of cancer survivors who have participated in the LIVESTRONG at the YMCA program. Even when one considers the limitations of this analysis, the results are an indicator of the value of this community-based intervention and its support of cancer survivors. These findings support the role of exercise as an intervention that has a positive impact on the health of cancer survivors.

In order to refine our evidence base related to effective programming for cancer survivors, we identified areas that warrant further research, including (1) the need for investigations that define clinically significant changes and/or endpoints for the PROMIS-29 Profile quality of life domains and physical fitness measures in cancer survivors; (2) the need for longitudinal studies to see if these positive changes persist over time; and (3) additional exploration of the impact community exercise programs have on cancer survivorship. Additionally, as our health-care systems continue to transform, clinically relevant data as are generated by community organizations such as the LIVESTRONG at the YMCA program will benefit patients through clinical record integration.

Policy development that supports community exercise programming for cancer survivors and promotes the integration of the data generated by these programs into the clinical health record by professional organizations, health-care systems, insurers, and government agencies could facilitate the extension of the cancer care team to link healthcare and community cancer care providers and contribute to bringing a holistic system to cancer survivor care.

\section{Acknowledgement}

The authors would like to thank Sheri Cognetti, Regional Director of the LIVESTRONG at the YMCA Program and Senior Program Director at the New Jersey Fanwood-Scotch Plains YMCA, for facilitating the data sharing agreement with the YMCA sites.

\section{Disclosure}

The authors have no conflicts of interest to disclose.

\section{References}

American Cancer Society. (2016). Cancer treatment \& survivorship facts \& figures. Retrieved from http://www. cancer.org/acs/groups/content/@research/documents/ document/acspc-048074.pdf

American Society of Clinical Oncology. (2016). Physical activity tips for survivors. Retrieved from http://www.cancer. net/survivorship/healthy-living/physical-activity-tipssurvivors

Baechle, T. R., \& Wathen, D. (2008). Resistance training. In T. R. Baechle \& R. W. Earle (Eds.), Essentials of strength training and conditioning (3rd ed., pp. 381-412). Champaign, Illinois: Human Kinetics.

Cella, D., Yount, S., Rothrock, N., Gershon, R., Cook, K., Reeve, B.,...Rose, M. (2007). The Patient-Reported Outcomes Measurement Information System (PROMIS): Progress of an NIH Roadmap cooperative group during its first two years. Medical Care, 45(5 suppl 1), S3-S11. https:// doi.org/10.1097/01.mlr.0000258615.42478.55

Centers for Disease Control and Prevention. (2014). State Cancer Registry and the CDC's National Program of Cancer Registries Cancer Surveillance System (NPCRCSS). Retrieved from http://statecancerprofiles.cancer. gov/incidencerates/index.php? stateFIPS $=42 \&$ cancer $=0$ $55 \&$ race $=00 \&$ type $=$ incd

Centers for Disease Control and Prevention. (2015). Physical activity and health. Retrieved from https://www.cdc. gov/physicalactivity/basics/pa-health/index.htm

Centers for Disease Control and Prevention. (2018). National Center for Chronic Disease Prevention and Health Promotion: Physical activity prevents chronic disease. Retrieved from https://www.cdc.gov/chronicdisease/resources/infographic/physical-activity.htm

Deckx, L., van den Akker, M., Metsemakers, J., Knottnerus, A., Schellevis, F., \& Buntinx, F. (2012). Chronic diseases among older cancer survivors. Journal of Cancer Epidemiology, 2012, Article ID 206414. https://doi. org/10.1155/2012/206414

Duregon, F., Vendramin, B., Bullo, V., Gobbo, S., Cugusi, L., Di Blasio, A.,...Ermolao, A. (2018). Effects of exercise on cancer patients suffering chemotherapy-induced peripheral neuropathy undergoing treatment: A systematic review. Critical Reviews in Oncology/Hematology, 121, 90-100. https://doi.org/10.1016/j.critrevonc.2017.11.002

Emilio, E. J., Hita-Contreras, F., Jiménez-Lara, P. M., LatorreRomán, P., \& Martinez-Amat, A. (2014). The association of flexibility, balance, and lumbar strength with balance ability: Risk of falls in older adults. Journal of Sports Science $\mathcal{E}$ Medicine, 13(2), 349-357. Retrieved from https:// www.ncbi.nlm.nih.gov/pubmed/24790489

Gillespie, L. D., Robertson, M. C., Gillespie, W. J., Sherrington, C., Gates, S., Clemson, L. M.,...Lamb, S. E. (2012). Interventions for preventing falls in older people living in the community. Cochrane Database Systematic Reviews, 2012(9), CD007146. https://doi.org/10.1002/14651858. CD007146.pub3

Hann, D. M., Jacobsen, P. B., Azzarello, L. M., Martin, S. C., Curran, S. L., Fields, K. K.,...Lyman, G. (1998). Measurement of fatigue in cancer patients: Development and validation of the Fatigue Symptom Inventory. Quality of Life Research, 7(4), 301-310. https://doi. org/10.1023/A:1008842517972

Heston, A. H., Schwartz, A. L., Justice-Gardiner, H., \& 
Hohman, K. H. (2015). Addressing physical activity needs of survivors by developing a community-based exercise program: LIVESTRONG ${ }^{\circledR}$ at the YMCA. Clinical Journal of Oncology Nursing, 19(2), 213-217. https://doi. org/10.1188/15.CJON.213-217

Holmes, M. D., Chen, W. Y., Feskanich, D., Kroenke, C. H., \& Colditz, G. A. (2005). Physical activity and survival after breast cancer diagnosis. JAMA, 293(20), 2479-2486. https://doi.org/10.1001/jama.293.20.2479

Howlader, N., Noone, A. M., Krapcho, M., Miller, D., Bishop, K., Altekruse, S.,...Cronin, K. (2016). SEER Cancer Statistics Review, 1975-2013. Bethesda, MD: National Cancer Institute. Retrieved from http://seer.cancer.gov/ csr/1975_2013

International Breast Cancer Paddlers' Commission. (2016). International Breast Cancer Paddlers' Commission. Retrieved from http://www.ibcpc.com/index.htm

Kleckner, I. R., Kamen, C., Gewandter, J. S., Mohile, N. A., Heckler, C. E., Culakova, E.,...Mustian, K. M. (2018). Effects of exercise during chemotherapy on chemotherapyinduced peripheral neuropathy: A multicenter, randomized controlled trial. Supportive Care in Cancer, 26(4), 1019-1028. https://doi.org/10.1007/s00520-017-4013-0

Meyerhardt, J. A., Heseltine, D., Niedzwiecki, D., Hollis, D., Saltz, L. B., Mayer, R. J.,...Fuchs, C. S. (2006). Impact of physical activity on cancer recurrence and survival in patients with stage III colon cancer: Findings from CALGB 89803. Journal of Clinical Oncology, 24(22), 3535-3541. https://doi.org/10.1200/JCO.2006.06.0863

Mishra, S. I., Scherer, R. W., Geigle, P. M., Berlanstein, D. R., Topaloglu, O., Gotay, C. C., \& Snyder, C. (2012). Exercise interventions on health-related quality of life for cancer survivors. Cochrane Database Systematic Reviews, 2012(8), CD007566. https://doi.org/10.1002/14651858. CD007566.pub2

Molinaro, J., Kleinfeld, M., \& Lebed, S. (1986). Physical therapy and dance in the surgical management of breast cancer. A clinical report. Physical Therapy, 66(6), 967-969. https://doi.org/10.1093/ptj/66.6.967

Musanti, R., \& Murley, B. (2016). Community-based exercise programs for cancer survivors. Clinical Journal of Oncology Nursing, 20(6 suppl), S25-S30. https://doi. org/10.1188/16.CJON.S2.25-30

National Cancer Institute. (2015). Cancer Stat Facts: Cancer of any site. Retrieved from http://seer.cancer.gov/statfacts/html/all.html

National Cancer Institute. (2017). Physical activity and cancer. Retrieved from https://www.cancer.gov/about-cancer/causes-prevention/risk/obesity/physical-activityfact-sheet

Office of Disease Prevention and Health Promotion. (2018). Activity guidelines for Americans. Retrieved from http:// health.gov/paguidelines/

Oncology Nursing Society. (2016). Get Up, Get Moving. Retrieved from https://www.ons.org/practice-resources/ get-up-get-moving

Rajotte, E. J., Yi, J. C., Baker, K. S., Gregerson, L., Leiserowitz, A., \& Syrjala, K. L. (2012). Community-based exercise program effectiveness and safety for cancer survivors. Journal of Cancer Survivorship, 6(2), 219-228. https:// doi.org/10.1007/s11764-011-0213-7

Rand Corporation. (2016). Terms and conditions for using the 36 -item short form survey (SF-36). Retrieved from http://www.rand.org/health/surveys_tools/mos/36item-short-form/terms.html

Rock, C. L., Doyle, C., Demark-Wahnefried, W., Meyerhardt, J., Courneya, K. S., Schwartz, A. L.,...Gansler, T. (2012). Nutrition and physical activity guidelines for cancer survivors. CA: A Cancer Journal for Clinicians, 62(4), 243274. https://doi.org/10.3322/caac.21142

Roy, S., Vallepu, S., Barrios, C., \& Hunter, K. (2018). Comparison of comorbid conditions between cancer survivors and age-matched patients without cancer. Journal of Clinical Medicine Research, 10(12), 911-919. https://doi. org/10.14740/jocmr3617w

Schmidt, K., Vogt, L., Thiel, C., Jäger, E., \& Banzer, W. (2013). Validity of the six-minute walk test in cancer patients. International Journal of Sports Medicine, 34(7), 631-636. https://doi.org/10.1055/s-0032-1323746

Schmitz, K. H., Courneya, K. S., Matthews, C., Demark-Wahnefried, W., Galvão, D. A., Pinto, B. M.,...Schwartz, A. L. (2010). American College of Sports Medicine roundtable on exercise guidelines for cancer survivors. Medicine $\mathcal{E}$ Science in Sports \& Exercise, 42(7), 1409-1426. https:// doi.org/10.1249/MSS.0b013e3181e0c112

Scott, D. A., Mills, M., Black, A., Cantwell, M., Campbell, A., Cardwell, C. R.,...Donnelly, M. (2013). Multidimensional rehabilitation programmes for adult cancer survivors. Cochrane Database of Systematic Reviews, 2013(3), CD007730. https://doi.org/10.1002/14651858. CD007730.pub2

Shiraz, F., Rahtz, E., Bhui, K., Hutchison, I., \& Korszun, A. (2014). Quality of life, psychological wellbeing and treatment needs of trauma and head and neck cancer patients. British Journal of Oral and Maxillofacial Surgery, 52(6), 513-517. https://doi.org/10.1016/j.bjoms.2014.03.019

Smith, J. L., Pollack, L. A., Rodriguez, J. L., Hawkins, N. A., Smith, T., Rechis, R.,...Stone-Wiggins, B. (2013). Assessment of the status of a National Action Plan for Cancer Survivorship in the USA. Journal of Cancer Survivorship, 7(3), 425-438. https://doi.org/10.1007/s11764-013-0276-8

Spence, R. R., Heesch, K. C., \& Brown, W. J. (2010). Exercise and cancer rehabilitation: A systematic review. Cancer Treatment Reviews, 36(2), 185-194. https://doi. org/10.1016/j.ctrv.2009.11.003

Springer, B. A., Marin, R., Cyhan, T., Roberts, H., \& Gill, N. W. (2007). Normative values for the unipedal stance test with eyes open and closed. Journal of Geriatric Physical Therapy, 30(1), 8-15. https://doi.org/10.1519/00139143200704000-00003

Staff, N. P., Grisold, A., Grisold, W., \& Windebank, A. J. (2017). Chemotherapy-induced peripheral neuropathy: A current review. Annals of Neurology, 81(6), 772-781. https:// doi.org/10.1002/ana.24951

Stefani, L., Galanti, G., \& Klika, R. (2017). Clinical Implementation of Exercise Guidelines for Cancer Patients: Adaptation of ACSM's Guidelines to the Italian Model. Journal of Functional Morphology and Kinesiology, 2(1), 2-17. https://doi.org/10.3390/jfmk2010004

Susan G. Komen Race for the Cure. (2016). Susan G. Komen Race for the Cure. Retrieved from http://apps.komen. org/raceforthecure/

The Rehabilitation Institute of Chicago. (2015). Rehab Measures: Six Minute Walk Test. The Rehab Measures Database. Retrieved from http://www.rehabmeasures.org/ Lists/RehabMeasures/DispForm.aspx?ID=895 
Tran, H., Lin, C., Yu, F., Frederick, A., Mieras, M., \& Baccaglini, L. (2016). A multicenter study on the relative effectiveness of a 12-week physical training program for adults with an oncologic diagnosis. Supportive Care in Cancer, 24(9), 3705-3713. https://doi.org/10.1007/ s00520-016-3194-2

US Department of Health and Human Services. (2016). Health Measures: Transforming How Health is Measured - PROMIS Score and Interpret. Retrieved from http://www.healthmeasures.net/score-and-interpret/ interpret-scores/promis

Wildes, T. M., Depp, B., Colditz, G., \& Stark, S. (2016). Fall-risk prediction in older adults with cancer: An unmet need. Supportive Care in Cancer, 24(9), 3681-3684. https://doi. org/10.1007/s00520-016-3312-1

Winningham, M. L., \& MacVicar, M. G. (1988). The effect of aerobic exercise on patient reports of nausea. Oncology Nursing Forum, 15(4), 447-450. 